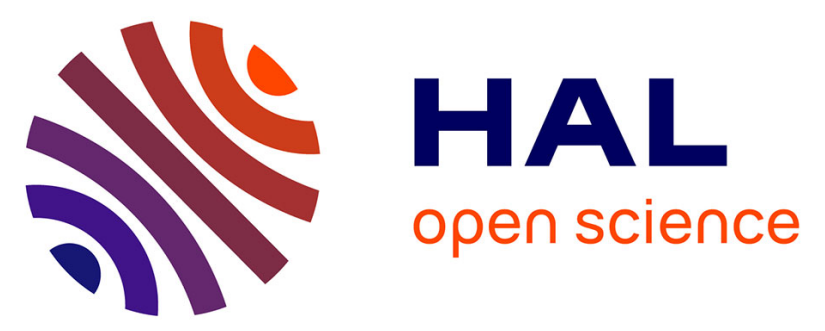

\title{
MRI anatomical mapping and direct stereotactic targeting in the subthalamic region: functional and anatomical correspondence in Parkinson's disease
}

Jean-Jacques J Lemaire, Jerome Coste, Lemlih $\times$ Ouchchane, Simone S Hemm, Philippe P Derost, Miguel M Ulla, Séverine S Siadoux, Jean J Gabrillargues, Franck F Durif, Jean J Chazal

\section{To cite this version:}

Jean-Jacques J Lemaire, Jerome Coste, Lemlih $\times$ Ouchchane, Simone S Hemm, Philippe P Derost, et al.. MRI anatomical mapping and direct stereotactic targeting in the subthalamic region: functional and anatomical correspondence in Parkinson's disease. International Journal of Computer Assisted Radiology and Surgery, 2007, 2 (2), pp.75-85. 10.1007/s11548-007-0124-2 . hal-01543092

\section{HAL Id: hal-01543092 https://hal.science/hal-01543092}

Submitted on 26 Jun 2017

HAL is a multi-disciplinary open access archive for the deposit and dissemination of scientific research documents, whether they are published or not. The documents may come from teaching and research institutions in France or abroad, or from public or private research centers.
L'archive ouverte pluridisciplinaire HAL, est destinée au dépôt et à la diffusion de documents scientifiques de niveau recherche, publiés ou non, émanant des établissements d'enseignement et de recherche français ou étrangers, des laboratoires publics ou privés. 


\title{
MRI anatomical mapping and direct stereotactic targeting in the subthalamic region: functional and anatomical correspondence in Parkinson's disease
}

\author{
Jean-Jacques Lemaire ${ }^{(1,2,6)} \cdot J_{\text {érôme Coste }}^{(1,2)} \cdot$ Lemlih Ouchchane $^{(3,2)} \cdot$ Simone \\ Hemm $^{(2)} \cdot$ Philippe Derost ${ }^{(4)} \cdot$ Miguel Ulla $^{(4)}$ Séverine Siadoux ${ }^{(5)} \cdot$ Jean \\ Gabrillargues $^{(5,2)} \cdot$ Franck Durif $^{(4)} \cdot$ Jean Chazal $^{(1)}$
}

(1) Service de Neurochirurgie A, CHU Clermont-Ferrand, Hôpital Gabriel Montpied, Clermont-Ferrand 63003, France

(2) Inserm, ERI 14, Clermont-Ferrand 63001, France

(3) Unité de Biostatistiques, télématique et traitement d'image, Univ Clermont 1, UFR Médecine, Clermont-Ferrand 63001, France

(4) Service de Neurologie A, CHU Clermont-Ferrand, Hôpital Gabriel Montpied, Clermont-Ferrand 63003, France

(5) Service de Radiologie A, CHU Clermont-Ferrand, Hôpital Gabriel Montpied, Clermont-Ferrand 63003, France

(6) Corresponding author: jjlemaire@ chu-clermontferrand.fr

\begin{abstract}
Object Relationships between clinical effects, anatomy, and electrophysiology are not fully understood in DBS of the subthalamic region in Parkinson's disease. We proposed an anatomic study based on direct image-guided stereotactic surgery with a multiple source data analysis.

Materials and Methods A manual anatomic mapping was realized on coronal 1.5-Tesla MRI of 15 patients. Biological data were collected under local anesthesia: the spontaneous neuron activities and the clinical efficiency and the appearance of adverse effects. They were related to relevant current values $(\mathrm{mA})$, the benefit threshold (bt, minimal current leading an clear efficiency), the adverse effect threshold (at, minimal current leading an adverse effect) and the stimulation margin $(\mathrm{sm}=\mathrm{at}-\mathrm{bt})$; they were matched with anatomy.

Results We found consistent relationships between anatomy and biological data. The optimal stimulation parameters (low bt + high sm) were noted in the dorsolateral STN. The highest spontaneous neuron activity was found in the ventromedial STN. Dorsolateral (sensorimotor) STN seems the main DBS effector. The highest spontaneous neuron activity seems related to the anterior (rostral) ventromedial (limbic) STN.

Conclusion 1.5 Tesla images provide sufficiently detailed subthalamic anatomy for image-guided stereotactic surgery and may aid in understanding DBS mechanisms.
\end{abstract}

Keywords Image-guided surgery, STN-DBS, Stereotaxy, Brain mapping 


\section{Introduction}

Deep brain stimulation (DBS) of the subthalamic nucleus (STN) is widely accepted as treatment of symptoms related to severe idiopathic Parkinson's disease (PD). It dramatically alleviates motor fluctuations and dyskinesia and leads to a significant reduction of dopatherapy [1-6]. DBS seems to act mainly through a functional inactivation of the STN, the surgical target, through a complex modulation [7-14]. However, neighboring structures, particularly the zona incerta (ZI) and Forel's fields, are strongly suspected to participate in the clinical effect [7,15-20]. To investigate relationships between anatomic structures and effects we proposed a study based on direct image-guided stereotactic surgery. Nuclei and bundles were identified during the planning on coronal T2-weighted magnetic resonance imaging (MRI) images. This non probabilistic approach, without reference to traditional anatomic landmarks (the anterior and posterior white commissures, ACPC), is used in routine in our institution for DBS surgery [21,22]. It allows a 3D trajectory optimization taking into account the neighbor structures around the target. Acute stimulation tests and electrophysiological recordings were performed intra operatively, the patient awake under local anesthesia, affording a side by side analysis of the subthalamic region. In a prospective study, we aimed to analyze the multiple source data to evaluate the pertinence of the detailed anatomic approach and beyond to improve the patient care through a better knowledge of the mechanisms of DBS.

\section{Materials and Methods}

\section{Clinical material}

Fifteen consecutive patients, candidates for a DBS procedure according to the guidelines of the French National Agency of Accreditation and Evaluation in Health, were studied. Clinical, MRI and electrophysiological data were prospectively recorded between September 2004 and April 2005. Patients consisted of 8 males and 7 females suffering from a severe PD (values are expressed as mean \pm SD): age $62.1 \pm 7.5$ years, duration of disease $12.1 \pm 4.8$ years, Hoehn \& Yahr score in OFF state $2.3 \pm 0.9$ and ON state $2 \pm 0.9$ Unified Parkinson's Disease Rate Scale (UPDRS) in OFF state $27.5 \pm 11$ and ON state 8.6 \pm 5.8 , Levodopa response $70.3 \pm 13.9 \%$ and treatment (Levodopa Equivalent dose) $1012.7 \pm 437.6 \mathrm{mg}$. 


\section{Anatomical mapping and surgical planning}

A stereotactic frame (Leksell G frame, Elekta, Sweden) was placed with its repositioning kit (Leksell repositioning kit, Elekta, Sweden) under local anesthesia. The repositioning kit consisted in four posts with pre-positioned screw locations (the grooved hollows are numbered) and four calibrated fiber glass fixations inserted coaxially into calibrated hollows performed in the outer layer of the skull; for each post, the number of the grooved hollow used, the length of the fixation and the value of exceeding of the fixation out of post, were noted for repositioning. The frame was fitted to the cranial base along the Reid's (suborbital - external auditory meatus) baseline. A stereotactic MRI (with the stereotactic frame and its Coordinates Indicator Box) was performed (Sonata 1.5 Tesla, Siemens, Germany) in the coronal plane. A Cortex Attenuated Inversion Recovery sequence [23] was optimized for a better anatomical analysis without loss of geometrical accuracy (White matter Attenuated Inversion Recovery sequence, WAIR, Table 1; unpublished data).

Table 1 MRI sequences

\begin{tabular}{|c|c|c|c|c|c|c|c|}
\hline Sequences & $\begin{array}{l}\text { Repetition / } \\
\text { Echo time } \\
(\mathrm{msec})\end{array}$ & TI (msec) & voxel size $\left(\mathrm{mm}^{3}\right)$ & $\begin{array}{l}\text { Field of view } \\
(\mathrm{mm}) / \text { matrix }\end{array}$ & $\begin{array}{l}\text { Number } \\
\text { of images }\end{array}$ & Acquisition & Orientation \\
\hline $\begin{array}{l}\text { T2- weighted: White } \\
\text { matter attenuated } \\
\text { inversion } \\
\text { recovery (WAIR) }\end{array}$ & $4,500 / 13$ & 160 & $0.52 \times 0.62 \times 2$ & $270 / 512 \times 435$ & $\begin{array}{l}2 \times 15 \text { (two } \\
\text { interleaved series; } \\
\text { distance factor } \\
=2 \mathrm{~mm} \text { ) }\end{array}$ & $2 \times 9 \min 33 \mathrm{~s}$ & Coronal \\
\hline $\begin{array}{l}\text { T1-weighted: } \\
\text { 3D-MPRAGE }\end{array}$ & $2,140 / 3.93$ & NA & Isotropic: 1.3 & $320 / 480 \times 512$ & 120 (joined) & $8 \min 18 s$ & Axial \\
\hline
\end{tabular}

Characteristics of MRI sequences: pre operative, stereotactic, T2-weighted; post operative, non stereotactic, T1weighted, head coil, Specific Absorption Rate $=0.1 \mathrm{~W} / \mathrm{kg}$

It allowed visualizing both the stereotactic markers and the anatomy of nuclei and bundles. The stereotactic frame was then removed for patient comfort during the planning phase with stereotactic software (iPlan, BrainLAB, Germany). We segmented manually several structures of the subthalamic region (Fig. 1, top row, left image): STN, ZI, substantia nigra (SN), red nucleus (RN), ansa lenticularis (AL), Forel's fields (FF: H1 or thalamic fasciculus, H2 or lenticular fasciculus), the mamillo-thalamic bundle (MTB) and the periventricular region (PVR). The 
recognition of structures was achieved through a step by step approach based on the transfer of the anatomical knowledge on the structures revealed by the contrasts of the WAIR sequence. This was facilitated by the help of current anatomic and stereotactic books and 4.7 T MRI in-house anatomy software [24] allowing accurate 3D multi plane analysis. The anatomical stereotactic mapping was facilitated by the contrasts of the WAIR sequence, similar to the $4.7 \mathrm{~T}$ MRI inhouse anatomy software and the Schaltenbrand and Bailey's atlas (Fig. 1). Then the two trajectories (right and left) were planned as follows: double obliquity (ring and arc angles), entrance point on the second frontal gyrus, extra ventricular trajectory avoiding vessels and caudate nucleus and optimization of angles (ring and arc) to explore the anterior STN (in front of the anterior border of $\mathrm{RN}$ ) along the longest diameter from dorsolateral to ventromedial (i.e., the endpoint located close to $\mathrm{SN}$ ). We planned a $10-\mathrm{mm}$ exploration from the ventral thalamus (mainly the lateral border with the reticular nucleus) to the ventral anterior half of the STN (Fig. 1). The duration of the whole planning procedure (anatomical mapping of nine structures per side; trajectories) for the direct targeting (i.e., without reference to ACPC) was about $1 \mathrm{~h}$.

\section{Electrode implantation}

The following day the frame was repositioned under local anesthesia and antiparkinson-drug free conditions since midnight. X-ray controls during the procedure confirmed that the tracts followed the planning. Two quadripolar electrodes (DBS 3389, Medtronic, USA) were placed during the same procedure. For each electrode (right and left) we optimized the positioning of one contact (we always selected the contact $\mathrm{n} \bullet 1$, located just above the distal one or contact $\mathrm{n} \circ 0$; diameter $=$ $1.27 \mathrm{~mm}$, length $=1.5 \mathrm{~mm})$. For each side, the DBS electrode was implanted after an electrophysiological mapping with two exploration electrodes (Alpha Omega, Israel): one on the planned tract (named central) and a parallel one $2 \mathrm{~mm}$ anteriorly (named anterior). We used a "closed dura mater" approach with water-air tight guides (Bengun, Immi, France) to minimize the brain shift due to cerebrospinal fluid leakage during the introduction of guide tubes. The electrophysiological analysis was performed along the lower 10-mm of the two tracts, from proximal to distal (from -10 to $0 \mathrm{~mm}$ position). We first recorded the spontaneous extracellular neuronal activity every $0.5 \mathrm{~mm}$ (mean duration $\cong 60 \mathrm{~s}$ ) using the recording contact of the exploration electrode (microelectrode contact, diameter $=25 \mu \mathrm{m}$, length $=100 \mu \mathrm{m})$. 

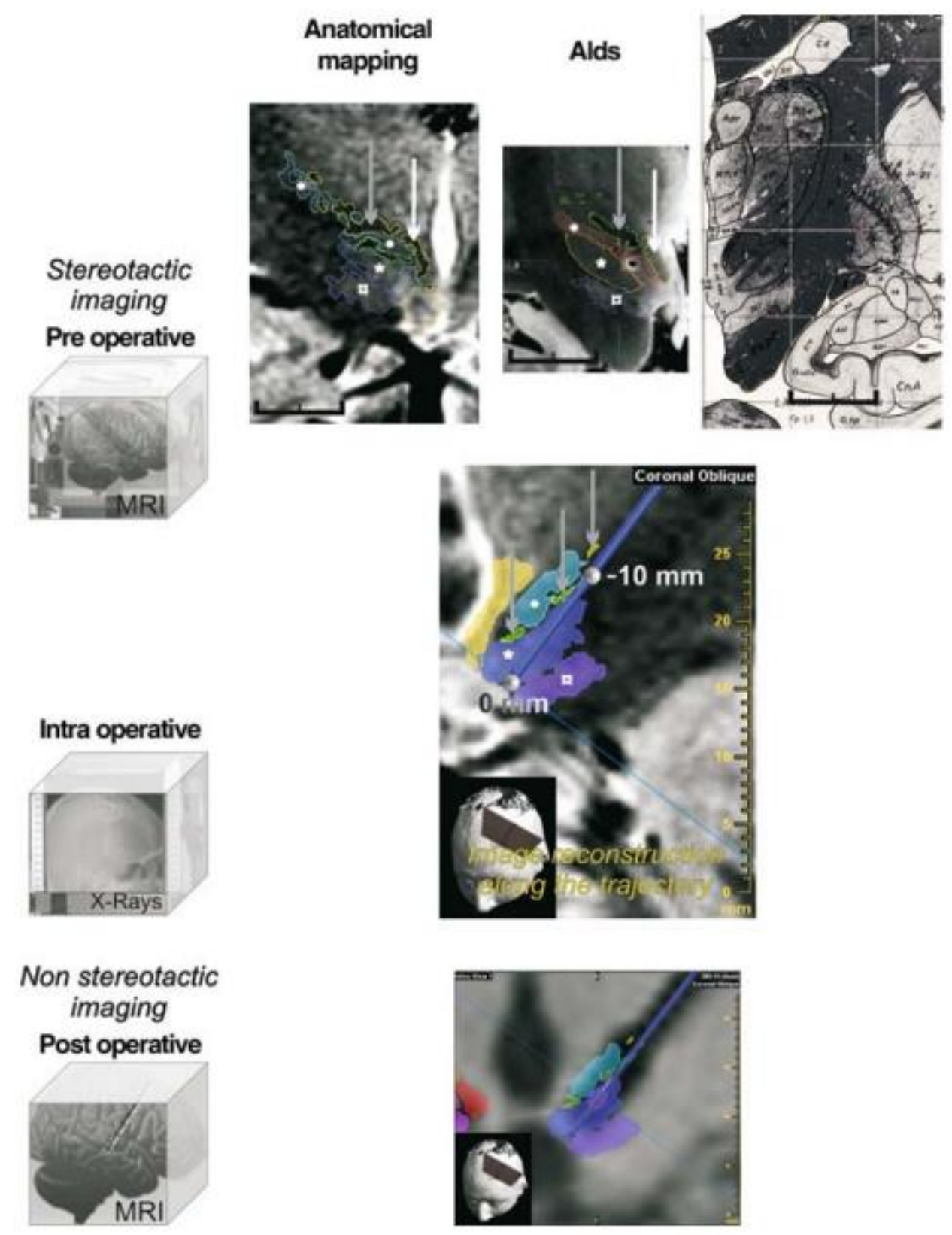

Figure 1 Overview of the method allowing image analysis. Top row (black horizontal line $=10 \mathrm{~mm}$ ): left, anatomical mapping on the pre operative MRI images (WAIR sequence, voxel $=0.52 \times 0.62 \times 2 \mathrm{~mm} 3$ ), Substantia nigra (*), subthalamic nucleus (*), zona incerta plus Arnold's net (०), Forel's fields (grey arrows) and mamillo-thalamic bundle (white arrows); middle and right, visual aids used for the recognition of anatomy, respectively, approximate slice of 4.7T MRI in-house anatomy software (isotropic voxel = 253 $\mu \mathrm{m3}$; anatomic specimen preparation) and plate of the Schaltenbrand and Bailey Atlas. Intermediate row reconstructed MRI slice along the planned trajectory and merged anatomical mapping. Bottom row the DBS electrode is visible as a black artifact; the reference contact location, calculated on the postoperative stereotactic X-ray control, is displayed as a segment (light purple) 
Then, after retraction of the recording contact and moving out to $-10 \mathrm{~mm}$ position, acute stimulation tests up to $4 \mathrm{~mA}$ were performed every $1 \mathrm{~mm}$ from proximal to distal. Therefore, the stimulation contact of the exploration electrode was used (macro-electrode contact, diameter $=$ $550 \mu \mathrm{m}$, length $=1.2 \mathrm{~mm}$; maximal current density $\cong 1.9 \mathrm{~mA} / \mathrm{mm} 2$, frequency $=130 \mathrm{~Hz}$, pulse width $\cong 60 \mu \mathrm{s}$ ). At each checkpoint, the clinical benefit (neurologist evaluation) and the adverse effects were recorded while increasing ( $\mathrm{step}=0.2 \mathrm{~mA}$ ) the stimulation current. The quality of improvement was quantified with a subjective scale, the improvement degree, estimatedas follows: $0=0 \%, 1=25 \%, 2=50 \%, 3=75 \%$ and $4=100 \%$ (intermediate values between two adjacent entire values were accepted). The current thresholds linked to clinical benefit (benefit threshold, bt) and to adverse effects (adverse effect threshold, at) were noticed as well as the difference between the adverse effect threshold and the benefit threshold, the stimulation margin $(\mathrm{sm}=\mathrm{at}-\mathrm{bt})$. If no adverse effect was noted till $4 \mathrm{~mA}$, the adverse effect threshold was defined as $4 \mathrm{~mA}$ by design, delivering a standardized range of stimulation margins $(\mathrm{smmin}=0 \mathrm{~mA}, \mathrm{smmax}$ $=4 \mathrm{~mA}$ ). The stimulation tests were stopped when we obtained the best clinical improvement (improvement degree > 2) with the lowest current, often before the end point of the tract. We considered that we were past the optimal region if the benefit threshold (bt) increased and/or the stimulation margin $(\mathrm{sm})$ decreased significantly as compared to these values at the optimal point. A DBS electrode was placed on the tract where we found the best stimulation parameters: the lowest benefit threshold (bt) with a high stimulation margin $(\mathrm{sm})$. The center of contact $n^{\circ} 1$ (named reference contact) was placed on this optimal point. The DBS electrode placement was based strictly on the stimulation effects, without taking into account the extracellular neuronal activity (Fig. 2). A stereotactic X-ray control (based on Leksell Coordinates Indicator Box) was performed at the end of the procedure to check the electrode positions before removal of the frame. 


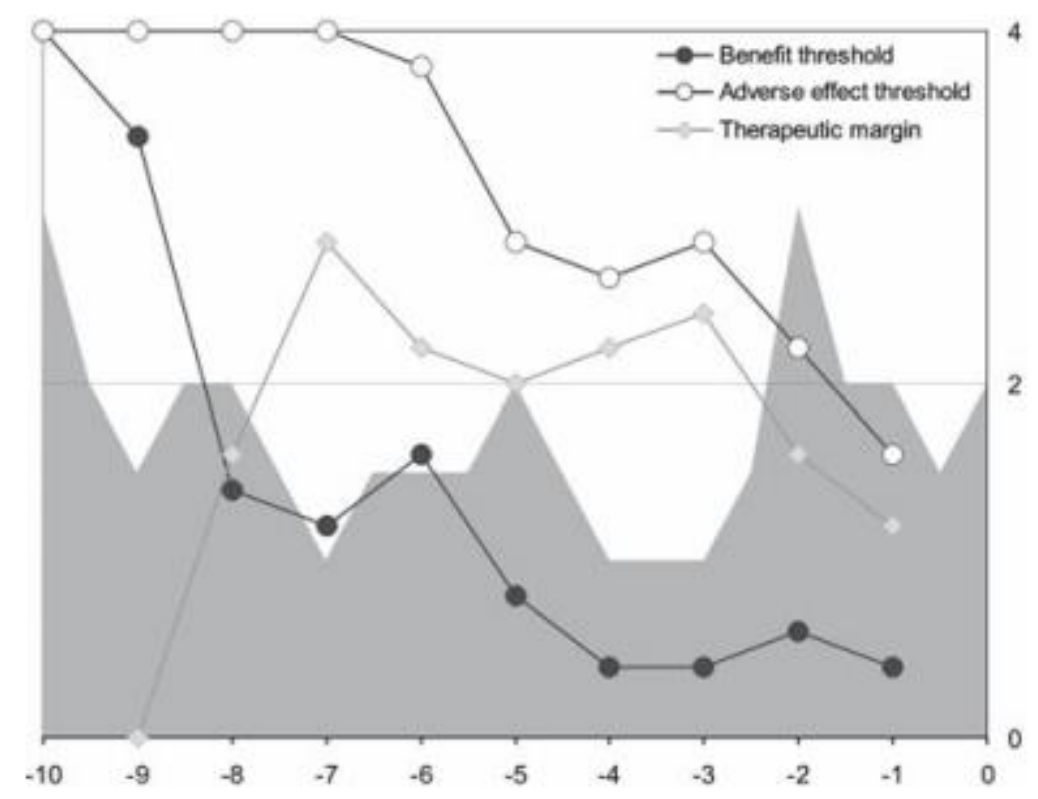

Figure 2 Example of intra operative clinical and electrophysiological mapping. The exploration was performed along the distal 10-mm of the planed trajectory going through the subthalamic region. The clinical efficiency was assessed every $1 \mathrm{~mm}$ giving two main electro-clinical parameters (y-axis; $\mathrm{mA}$ ): the benefit threshold (black dot) and the therapeutic margin (grey lozenge); minimal current leading an adverse effect (white dot). Note that the stimulation tests were stopped $1 \mathrm{~mm}$ before the end point because of both a low adverse effect threshold and a reduced therapeutic margin. The reference contact was placed on the optimal clinical efficiency zone (hatched grey area), with both a low benefit threshold and a high therapeutic margin. The neuronal activity is plotted in background (grey area, recording every $0.5 \mathrm{~mm}$; the higher the spike, the higher the activity)

\section{Post operative data}

An early (within 2 days) MRI control (Table 1) was performed to identify asymptomatic complications and to confirm position of DSB electrodes in the planned trajectories. The visualization of the tracts selected for DBS electrode placement showed that all of them were located within the artifact visible on the postoperative MRI (Fig. 1). After this control, a neuropacemaker (Kinetra, Medtronic, USA) was implanted in the abdominal wall, under general anesthesia. 
5. Classification of electrophysiological recordings and definition of stimulation related parameters

The electrophysiological recordings were analyzed on and/or off line by an electro physiologist and a neurosurgeon both blind to the anatomy. We used a qualitative classification of multi-unit recordings, based on the visual evaluation of 30-s consecutive and spontaneous cell activity replayed on a 5-s frame display (MicroGuide, Alpha-Omega, Israel). Six patterns of neuronal activity were defined, regardless of the signal amplitude, considering relative regularity and frequency, from the lowest to the highest (Fig. 3) : $0=$ background noise, $1=$ isolated activity, 2A $=$ irregular low activity, $2 \mathrm{~B}=$ irregular moderate activity, $2 \mathrm{C}=$ irregular high activity, $3=$ low burst-like activity, $4=$ high burst-like activity and $5=$ permanent tonic activity. The activity was considered as monotonous if we noted only one type of pattern on whole recording, otherwise it was variable. The stimulation related parameters were the benefit threshold (mA), the adverse effect threshold (mA) and the difference so called the stimulation margin (mA).

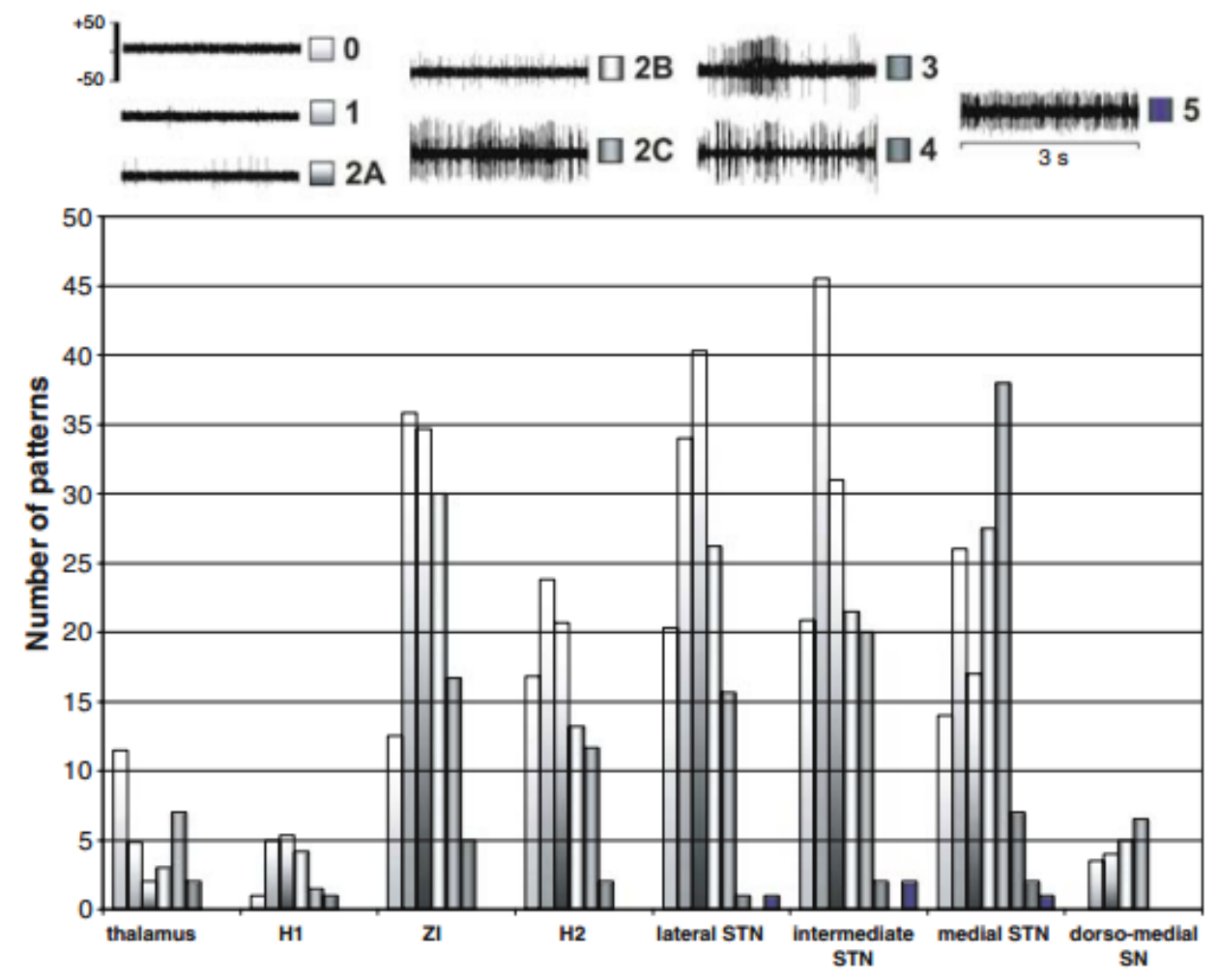

Figure 3 Electrophysiological data: top classification of typical patterns (multi-unit recordings) of extracellular neuron activity (y-axis, $\mu V$ ); bottom distribution of patterns according to structures (see text for abbreviations; $y$ axis $=$ number of patterns irrespective of trace type, monotonous or variable, minute contribution structures are removed, $P V R$ and $A L)$ 
Rigidity and/or tremor were assessed mainly on the superior limb and in particular the wrist or the elbow. The related improvement degree and adverse effects, gaze, vegetative, sensitive and motor were recorded.

6. Matching electrophysiological and clinical intra operative data with the anatomical MRI space

The anatomical space was defined for each patient on the pre operative MRI where the anatomical mapping was done. For a detailed analysis allowed by the images, the STN was divided in three sub parts in the frontal plane according to its functional territories [25]: the lateral (or dorso-lateral), the intermediate and the medial (or ventromedial) regions. The clinical and electrophysiological data were matched with the anatomical structures as follows: each checkpoint (related to stimulation test or electrophysiological recording) was attributed to one structure according to its position along the tract (from -10 to $0 \mathrm{~mm}$ ); if a checkpoint was close to several structures (two or three) it was attributed to each with a weight proportional to the number of structures implied, i.e., $1 / 2$ for two structures or $1 / 3$ for three structures; when a checkpoint was attributed to only one structure the weight was obviously set to 1. As a consequence, the counting for description and analysis, concerning checkpoints, used decimal numbers (see Tables 2, 3)

Table 2 Stimulation related parameters: for the target symptoms (rigidity, tremor)

\begin{tabular}{|c|c|c|c|c|c|c|c|c|}
\hline \multirow[t]{3}{*}{ Structures } & \multicolumn{3}{|l|}{ Rigidity assessment } & \multicolumn{2}{|c|}{ Tremor assessment } & \multicolumn{3}{|c|}{ Whole assessment of target symptoms } \\
\hline & \multirow[t]{2}{*}{$\begin{array}{l}\text { Noticed effects } \\
\text { out off } \\
\text { performed tests } \\
\text { (ratio) }\end{array}$} & \multirow[t]{2}{*}{$\begin{array}{l}\text { Benefit } \\
\text { threshold } \\
\text { (mA mp) } \\
\text { mean }( \pm S D)\end{array}$} & \multirow[t]{2}{*}{$\begin{array}{l}\text { Improvement } \\
\text { degroe } \\
\text { mean }( \pm S D)\end{array}$} & \multirow[t]{2}{*}{$\begin{array}{l}\text { Noticed effects } \\
\text { out of / } \\
\text { performed tests }\end{array}$} & \multirow[t]{2}{*}{$\begin{array}{l}\text { Benefit } \\
\text { threshold } \\
\text { (mAmp) } \\
\text { mean }( \pm S D)\end{array}$} & \multirow[t]{2}{*}{$\begin{array}{l}\text { Noticed effects } \\
\text { out off } \\
\text { performed tests } \\
\text { (ratio) }\end{array}$} & $\begin{array}{l}\text { Benefit } \\
\text { threshold }\end{array}$ & $\begin{array}{l}\text { Stimulation } \\
\text { margin }\end{array}$ \\
\hline & & & & & & & \multicolumn{2}{|c|}{$(\mathrm{mAmp})$ mean $( \pm \mathrm{SD})$} \\
\hline Thalamus & $4.33 / 10.83(39.98 \%)$ & $1.97( \pm 0.94)$ & $1.88( \pm 0.65)$ & $2 / 3$ & $2.80( \pm 0.28)$ & $6.33 / 12.83(49.34 \%)$ & $2.23( \pm 0.87)$ & $1.67( \pm 1.02)$ \\
\hline $\mathrm{H1}$ & $5.17 / 10.5(42.24 \%)$ & $1.83( \pm 1.13)$ & $1.92( \pm 0.97)$ & 000 & NA & $5.17 / 10.5(49.24 \%)$ & $1.83( \pm 1.13)$ & $1.91( \pm 1.01)$ \\
\hline $\mathrm{ZI}$ & $35.17 / 53.5(65.74 \%)$ & $1.70( \pm 0.93)$ & $2.16( \pm 0.69)$ & $2 / 2$ & $1.41( \pm 0.28)$ & $36.67 / 54.5(67.28 \%)$ & $1.70( \pm 0.91)$ & $1.85( \pm 0.92)$ \\
\hline $\mathrm{H} 2$ & $33.17 / 41.5(79.93 \%)$ & $1.10( \pm 0.54)$ & $2.30( \pm 0.59)$ & $2 / 2$ & $1.10( \pm 0.41)$ & $33.67 / 41.5(81.13 \%)$ & $1.12( \pm 0.54)$ & $1.82( \pm 0.82)$ \\
\hline Lateral STN & $52.67 / 53.17(99.06 \%)$ & $0.78( \pm 0.44)$ & $2.51( \pm 0.56)$ & $5 / 5$ & $0.96( \pm 0.50)$ & $55.67 / 56.17(99.11 \%)$ & $0.80( \pm 0.45)$ & $1.78( \pm 0.88)$ \\
\hline Intermediate STN & $32 / 32(100 \%)$ & $0.72( \pm 0.30)$ & $2.86( \pm 0.68)$ & $1 / 1$ & 1.40 & $32 / 32(100 \%)$ & $0.72( \pm 0.30)$ & $1.20( \pm 0.56)$ \\
\hline Medial STN & $7 / 7(100 \%)$ & $0.80( \pm 0.40)$ & $2.93( \pm 0.93)$ & 010 & NA & $7 / 7(100 \%)$ & $0.80( \pm 0.40)$ & $1.14( \pm 0.63)$ \\
\hline SN & $0.5 / 0.5$ & 0.80 & 2 & 000 & NA & $0.5 / 0.5$ & 0.80 & 0.20 \\
\hline PVR & $0.5 / 0.5$ & 0.40 & 3.5 & 0 o & NA & $0.5 / 0.5$ & 0.40 & 2.00 \\
\hline $\mathrm{AL}$ & $0.5 / 0.5$ & 0.80 & 2 & 000 & NA & $0.5 / 0.5$ & 0.80 & 0.20 \\
\hline Total & $171 / 210(81.43 \%)$ & & & $12 / 13(92.31 \%)$ & & $178 / 216(82.40 \%)$ & & \\
\hline
\end{tabular}

...... 
Lemaire et al. 2007

Table 3 Stimulation related parameters: for the adverse effects

\begin{tabular}{|c|c|c|c|c|c|c|c|c|}
\hline \multirow[t]{2}{*}{ Structures } & \multicolumn{2}{|l|}{ Gaxe effects } & \multicolumn{2}{|l|}{ Vegetative effects } & \multirow{2}{*}{\multicolumn{2}{|c|}{$\begin{array}{c}\text { Sensitive effects Motor effects } \\
\text { Noticed effects } \\
\text { out of/performed } \\
\text { tests (ratio) }\end{array}$}} & \multicolumn{2}{|l|}{ Whole adverse effects } \\
\hline & $\begin{array}{l}\text { Noticed effects } \\
\text { out of/performed } \\
\text { tests (ratio) }\end{array}$ & $\begin{array}{l}\text { Adverse effect } \\
\text { threshold } \\
\text { (mAmp) } \\
\text { mean }( \pm S D)\end{array}$ & $\begin{array}{l}\text { Noticed effects } \\
\text { out of/performed } \\
\text { tests (ratio) }\end{array}$ & $\begin{array}{l}\text { Adverse effect } \\
\text { threshold } \\
\text { (mAmp) } \\
\text { mean }( \pm S D)\end{array}$ & & & $\begin{array}{l}\text { Noticed effects } \\
\text { out of/performed } \\
\text { tests (ratio) }\end{array}$ & $\begin{array}{l}\text { Adverse effect } \\
\text { threshold } \\
\text { (mAmp) } \\
\text { mean }( \pm S D)\end{array}$ \\
\hline Thalamus & $0 / 12.83(0 \%)$ & NA & $0 / 12.83(0 \%)$ & NA & $0 / 12.83(0 \%)$ & $1.5 / 12.83(11.69 \%)$ & $1.5 / 12.83(11.70 \%)$ & $2.87( \pm 0.92)$ \\
\hline $\mathrm{Hl}$ & $1 / 10.5(9.52 \%)$ & $3.00( \pm 0.20)$ & $1.33 / 10.5(12.67 \%)$ & $3.33( \pm 0.36)$ & $0 / 10.5(0 \%)$ & $0 / 10.5(0 \%)$ & $1.83 / 10.5$ (17.43\%) & $3.29( \pm 0.29)$ \\
\hline $\mathrm{ZI}$ & $9.33 / 54.5(17.12 \%)$ & $3.08( \pm 0.56)$ & $6.17 / 54.5(11.32 \%)$ & $2.63( \pm 0.65)$ & $1 / 54.5(1.83 \%)$ & $3.5 / 54.5(6.42 \%)$ & $19 / 54.5(34.86 \%)$ & $2.93( \pm 0.63)$ \\
\hline $\mathrm{H} 2$ & $5.33 / 42.5(12.54 \%)$ & $2.79( \pm 0.67)$ & $23.1742 .5(54.52 \%)$ & $2.40( \pm 0.65)$ & $3.5 / 42.5(8.24 \%)$ & $0 / 42.5(0 \%)$ & $29.5 / 42.5(69.41 \%)$ & $2.53( \pm 0.66)$ \\
\hline Lateral STN & $19.33 / 58.17(33.23 \%)$ & $2.13( \pm 0.79)$ & $29.83 / 58.17(51.28 \%)$ & $2.37( \pm 0.88)$ & $1.5 / 58.17(2.58 \%)$ & 0/58.17 (0\%) & $49.67 / 58.17(85.39 \%)$ & $2.30( \pm 0.83)$ \\
\hline Intermediak STN & $12.5 / 35(35.71 \%)$ & $1.68( \pm 0.28)$ & $25.5 / 35(72.86 \%)$ & $1.99( \pm 0.59)$ & $0 / 35(0 \%)$ & $0 / 35(0 \%)$ & $35 / 35(100 \%)$ & $1.91( \pm 0.54)$ \\
\hline Medial STN & $3 / 8(37.50 \%)$ & $1.87( \pm 0.41)$ & $5 / 8(62.50 \%)$ & $1.88( \pm 0.54)$ & 0/8 (0\%) & OV8 (0\%) & $8 / 8(100 \%)$ & $1.88( \pm 0.46)$ \\
\hline SN & $0.5 / 0.5$ & 1 & $0 \times 0.5$ & NA & 00.5 & 0 0.5 & 00.5 & 1 \\
\hline PVR & $0.5 / 0.5$ & 2.4 & 00.5 & NA & 00.5 & 010.5 & 00.5 & 2.4 \\
\hline $\mathrm{AL}$ & $0.5 / 0.5$ & 1 & 00.5 & NA & $0 / 0.5$ & 0 os & 00.5 & 1 \\
\hline Total & $52 / 223(23.32 \%)$ & & $91 / 223(40.81 \%)$ & & $6 / 223(2.69 \%)$ & $5 / 223(2.24 \%)$ & $147 / 223(65.92 \%)$ & \\
\hline
\end{tabular}

Values (NA not applicable; SD standard deviation; number of noticed effects and number of performed tests) according to structures (see text for abbreviations)

\section{Statistical analysis}

We hypothesized that there were relationships between the anatomical structures and the clinical and electrophysiological data. An electrode-tract approach was chosen for the analysis, each subthalamic region being considered as independent $(n=30)$, because of acute, side by side, intra operative conditions and independent right and left trajectories and structure surroundings (MRI anatomical based planning; we never used a symmetrical approach). There were 630 potential checkpoints for the neuron activity analysis $(n=15$ [patients] $\times 2$ [hemispheres $] \times\{10[\mathrm{~mm}] / 0.5$ $[\mathrm{mm}]+1$ [zero position]\}). For stimulation parameters analysis, there were 330 potential checkpoints $(\mathrm{n}=15$ [patients] $\times 2$ [hemispheres] $\times\{10[\mathrm{~mm}] / 1.0[\mathrm{~mm}]+1$ [zero position] $\})$. Relationships were analyzed as follows: 1०) between structures and spontaneous multi unit extracellular neuron activities; ${ }^{\circ}$ ) between structures and stimulation related data. Descriptive and statistical analysis were performed with SAS (SAS v8.02, SAS Institute Inc., USA): quantitative data displayed as mean \pm standard error were analyzed with one way analysis of variance (ANOVA), completed by a multiple comparison procedure computed using Tukey's method in case of overall significance, and with Student t test; qualitative data were analyzed with Pearson $\chi 2$ and Fischer exact tests. A statistical significance was accepted for a $\mathrm{P}$ value below 0.05 . 


\section{Results}

\section{Intra operative data}

Of the 630 potential checkpoints, 570 were related both to a structure and to a neuron activity. There were 60 missing checkpoints; three could not be defined anatomically on one tract, as there were small artifacts related to a hyper signal area $(<2 \mathrm{~mm})$. Fifty-seven recordings were not readable. The majority of 30-s recording traces were monotonous $(446$ times $=78.2 \%)$ and the minority was variable $(124$ times $=21.8 \%)$. The mean impedance of the 30 exploration electrodes was $0.54 \pm 0.28 \mathrm{Megohms}$ (at $1000 \mathrm{~Hz}$ ). The mean length of exploration tract during the stimulation tests was $6.83 \pm 1.42 \mathrm{~mm}$ (median value $=$ modal value $=6 \mathrm{~mm}$; out of the $10-\mathrm{mm}$ potential exploration). The efficiency assessment was related both to a structure and to stimulation data on 216 checkpoints $(65.5 \%$ from 330 potential checkpoints, 106 were not tested, 7 had no scaling of the benefit and one was not anatomically defined due to the artifact previously described). For the adverse effect assessment, 223 checkpoints were used (67.5\% from 330 potential checkpoints, 106 were not explored and one was not anatomically defined). The stimulation assessment focused mainly on rigidity (210 tests versus 13 tests for tremor). The main acute adverse effects related to stimulation were gaze (mainly by bilateral complex oculomotor, OM, dysfunction or by ipsilateral OM nerve paralysis) and vegetative troubles (nausea, moving sensation), respectively 23.3 and $40.8 \%$ of tests, followed by contralateral paresthesia and contralateral pyramidal-like rigidity, respectively 2.7 and $2.2 \%$ of tests.

\section{Relationships between structures and neuron activities}

We did not find any difference between the structures relative to types of recording traces, monotonous $(\mathrm{n}=446)$ or variable $(\mathrm{n}=124)(\chi 2$ test, $\mathrm{P}=0.2717$; Ansa Lenticularis and Peri Ventricular Region were removed due to their minute contribution, respectively $n=3$ and $n=1$ ). Considering only STN, we found a trend $(\mathrm{P}=0.08)$ towards monotonous type on intermediate STN and variable type on medial STN. The distribution of patterns according to structures is summarized in Fig. 3. The whole activity (patterns $1+2 \mathrm{~A}+2 \mathrm{~B}+2 \mathrm{C}+3+4+5$ ) became relatively more intense from ZI to medial STN. We could not analyze ( $\chi 2$ tests not applicable) the pattern distributions by structures (reference: whole pattern distribution) even if there was a 
shift toward an important neuron activity in medial STN and SN. The regroupings of patterns into two activity categories, low $(0,1,2 \mathrm{~A})$ and high $(2 \mathrm{~B}, 2 \mathrm{C}, 3,4,5)$, revealed the hyperactivity of medial STN $(\chi 2$ test, $\mathrm{P}<0.0001)$ and of $\mathrm{SN}(\chi 2$ test, $\mathrm{P} \cong 0.05)$. A selective analysis of checkpoints with exclusively low or high activity patterns (checkpoints with complex patterns, e.g. $1+2 \mathrm{C}$, removed) also showed the predominance of high activity patterns in medial STN and $\mathrm{SN}(\mathrm{n}=520$; monotonous or variable; $\chi 2$ test $\mathrm{P}=0.0007)$.

\section{Relationships between structures and stimulation related data}

The values of stimulation related parameters according to structures are summarized in Table 2 and 3. The mean rigidity benefit threshold and the mean whole benefit threshold decreased from thalamus to intermediate STN then slightly increased in medial STN, and conversely for the mean improvement degree until $\mathrm{H} 1$. The mean stimulation margin, the mean adverse effect threshold for gaze and neurovegetative troubles and the mean whole adverse effect threshold decreased from H1 to medial STN. The analysis of structures according to stimulation parameters revealed that $\mathrm{H} 2$ Forel's field and the three subparts of STN were significantly different relative to the structures located above (significant overall ANOVA, Tukey's P < 0.05); the only significant difference concerning a subpart of the STN, the intermediate STN, was relative to the stimulation margin of the lateral STN and ZI. The analysis of the distribution of effects, by stimulation parameters and by structures, showed a constant benefit on rigidity (and on tremor) in the STN, irrespective of improvement degree, and there were more gaze and vegetative troubles in STN than in neighbor structures located above (significant $\chi 2$ tests). Crossing data of benefit threshold and of stimulation margin we noted that the best region for a DBS stimulation was the lateral STN showing a low benefit threshold (mean less than $1 \mathrm{~mA}$ ) and a high stimulation margin (mean above $1.5 \mathrm{~mA}$ ) (Fig. 4). 


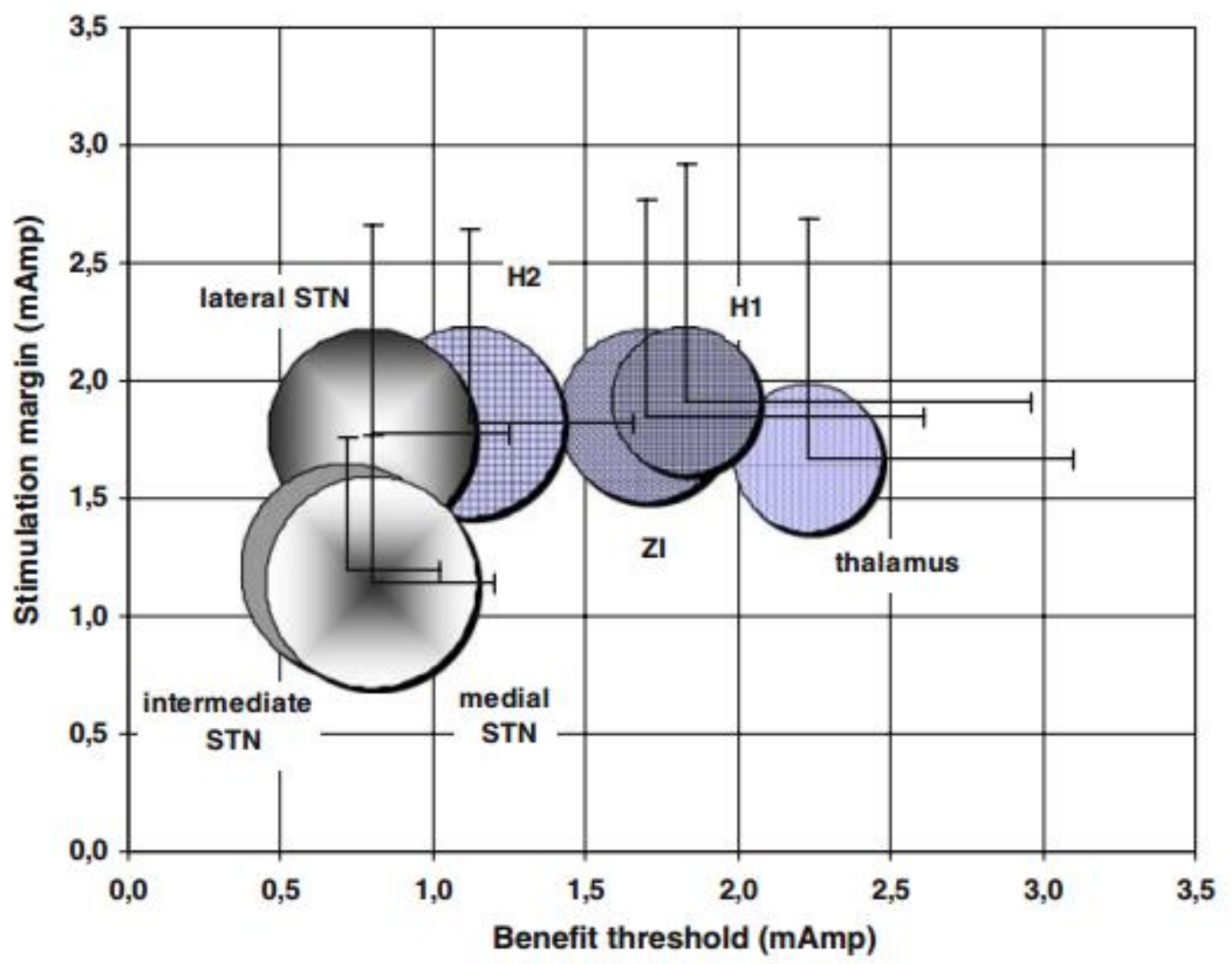

Figure 4 Relationships between the mean current values of the benefit threshold and of the stimulation margin, with their respective standard deviations (bold segments), function of structures (full circles, see text for abbreviations). The surface of circles is proportional to the percentage of benefit effects noticed during the intra operative assessment (see Table 2)

\section{Post operative findings}

The duration of the whole procedure of bilateral implantation was about $7 \mathrm{~h}$. The patients were all implanted bilaterally during the same procedure as we obtained a clear intra operative clinical efficiency with a mean maximal improvement degree of $2.95 \pm 0.63(\mathrm{n}=28 ; 2$ tracts had an incomplete scaling). There were no surgical complications. There were 28 electrodes (out of 30; 93.3\%; from $98 \%$ to $73 \%$ with a confidence interval of 5\%) placed on the central tract, which was anatomically optimized during the planning. Two electrodes were placed on the anterior tract.

Three months after surgery the mean percentage $( \pm \mathrm{SD})$ of motor improvement, achieved by the reference contacts selected intra operatively, was $61.7 \pm 4 \%(P<0.05)$. These results $(n=30)$ 
were measured under OFF-drug for at least $12 \mathrm{~h}$. The mean voltage was $2.7 \pm 0.5 \mathrm{~V}$ (frequency $=$ $130 \mathrm{~Hz}$, pulse width $=60 \mu \mathrm{s})$. Scores were based on a side by side assessment on subscales of UPDRS for akinesia, rigidity and tremor.

\section{Discussion}

The population in our study was comparable to others in the literature. Although relatively heterogeneous concerning age and disease, patients were consecutively enrolled without prejudice and following our institutional schedules.

\section{MRI subthalamic anatomy}

The WAIR sequence gave highly contrasted images in particular between nuclei and bundles allowing the anatomical mapping. This was facilitated by the stereotactic condition during the image acquisition, which not only allowed a direct reference to the surgical stereotactic space but also an improvement of the image quality. While the quality of signal can be increased by a long duration sequence of high resolution MRI it may also be compromised by any patient movements while in the head coil. The fixation of the frame to the head coil maintains the head stable during the acquisition and minimizes movement artifacts. To limit the patient discomfort, under local anaesthesia, without removal of antiparkinsonian drugs, we used a time adaptation of medication according to symptom fluctuations. Along with theoptimization of MRI acquisition, we favored reconstructed images along tracts, yielding an optimal analysis of relationships between tracts and structures without classical stereotactic atlas based referencing. These reconstructions also facilitated the reproducibility of trajectories relative to structures. The data provided by $4.7 \mathrm{~T}$ MRI in-house anatomy software with an isotropic voxel of $253 \mu \mathrm{m}$ side and a highly contrasted anatomy [24] helped with the determination of structures. The problem of missing slices and inconsistency between the different planes, well known with current classical atlas, was solved with the $3 \mathrm{D}$ anatomical reference allowing any reconstructions without loss of information 


\section{Analysis of spatial relationships}

We used a direct approach to study the spatial relationships on MRI, without reference to ACPC. We considered that the indirect approach of relative positioning methods could introduce non negligible geometrical errors known to exist with MRI [26]. Moreover, the MRI geometric distortion on current clinical MRI (1.5 Tesla machines) continues to be reduced toward tenths of millimetre [27,28], although in practice, for a given patient, one expects it below $1 \mathrm{~mm}$. Our results provide consistent relationships between MRI anatomy and clinical and electrophysiological data. The accurate analysis of the checkpoint location (stimulation tests and electrophysiological recordings) with reference to the planned exploration tracts was allowed by crossing multiple approaches. We first used reconstructed images along tracts allowing a direct 3D anatomical analysis. Then we controlled the geometry of the planned tracts by two different methods. First, intra operative X-rays checked that the tracts followed the planning (intra operative versus pre operative check; stereotactic matching with reference to the Leksell's geometrical space). Second, the analysis of DBS electrode location confirmed that all the studied tracts were really explored (intra operative versus post operative check; voxel to voxel matching). Post operative T1-weighted MRI was also proposed to determine the contact/electrode location $[29,30]$.

\section{Intra operative data collection}

Electrophysiology was performed in two tracts for three reasons: (1) the 2-mm thickness of frontal MRI slices could introduce a relative geometrical inaccuracy in the anteriorposterior direction; (2) only two tracts could be planned through STN because of the STN shape and the trajectory constraints; (3) one of the two guide tubes (used on tracts) was used as a security tool maintaining the brain during the removal of the one on the selected tract and its replacement by a DBS electrode.

The clinical assessments was restricted to standard motor and adverse effects because speech, behavior and cognitive functions could potentially be modified by a bilateral implantation of DBS electrodes [1-5] and are difficult to evaluate in routine surgical conditions. Even subjective, the quality of improvement scale gave consistent results with the anatomy. Its utilization is 
facilitated by a relative scoring acceptable in intraoperative conditions. Even limited to the motor assessment, it was difficult to distinguish between a dramatic improvement (degree of improvement $=3$ ) and a total disappearance of symptoms (degree of improvement $=4$ ) due to the severity of the symptom, the subjective clinician evaluation and because of sub thalamotomy effect when reaching the optimal site. This explains why we did not always reach the highest score of improvement (degree of improvement $=4 ; 100 \%$ of improvement).

The maximum stimulation threshold was fixed to $4 \mathrm{~mA}$ fitting clinical and ethical considerations, beyond which patient comfort could be compromised and data rendered useless. This led in return to an underestimation of the stimulation margin in absence of adverse effects. Thus the stimulation margin is not exactly the difference between benefit and adverse effect thresholds, a phenomenon more pronounced on a proximal position (e.g. thalamus) with fewer adverse effects (Table 2, 3). We fixed a 1-mm step between two stimulation tests based on our experience, as distinct effects are obtained with this distance, and on the hypothesis that a lower step would exaggerate the overlap of adjacent zones of stimulation (with the $1.2 \mathrm{~mm}$ length of our exploration electrode).

The recordings of extracellular neuron activity were planned with a fixed step of $0.5 \mathrm{~mm}$ in order to limit the duration of exploration without significant loss of information, since the length of the exploration electrode was $0.1 \mathrm{~mm}$. However, this compromise could result in underestimating the neuron activity. It is also questionable to seek a target with micrometric steps as most stereotactic tools or surgical environments are not still designed to reach such accuracy.

\section{Relationships between structures and clinical and electrophysiological data}

The distribution of spontaneous neuron activity patterns shows higher activities in STN and ZI whereas these are lower in FF, even if it was not statistically significant due to the variability of cell activities (Fig. 3). These results could be expected considering the complex micro organization of the subthalamic region [25,31,32], yet they fit with anatomy as FF is constituted by more bundles than cells. This qualitative analysis of multi-unit recordings could be used to detect electrophysiological boundaries, as already proposed with other methods [33,34], but also highlights the difficulties to reveal sharp boundaries [35]. We found the highest and most variable 
spontaneous neuronal activity in the anterior ventromedial STN and also the dorsal part of SN (Fig. 3). As the ventromedial STN is known to be limbic in primates [32] it could be potentially solicited particularly during surgery in awake conditions. Movement-related neuronal responses $[2,36,37]$ could define boundaries between the functional territories of STN.

The progressive increase of stimulation benefit from thalamus to STN (Tables 2, 3) was already reported with another method of location based on ACPC referencing [20]. The best DBS target determined by both, a low benefit threshold and a high stimulation margin, seems to be identified in the anterior dorsolateral STN (Fig. 4). This is in agreement with the sensorimotor territory of STN [25,38] and with the DBS clinical improvement mainly supported by motor effects [1-6], even if the posterior (caudal) part of the dorsolateral STN seems to be also a target [39]. Considering only the benefit threshold and the improvement degree (Table 1), intermediate STN could be the best target, in agreement with the functional segmentation of STN $[25,38]$. However, this has to be interpreted with caution due to the dramatic subthalamotomy effect from the entrance of STN. The main adverse effects, gaze and neurovegetative troubles, increase remarkably along tracts, linked with all the subthalamic structures. The gaze side effect could be explained by the proximity of OM fibers. The third cranial nerve fibers are at a distance of about $10 \mathrm{~mm}$ in the coronal plan from caudal and medial border of STN [40] and are progressively solicited. But the closest subthalamic OM connections are fibers going through $\mathrm{H} 2$ of which some emerged from STN [41]. The presence of all types of adverse effects in the upper part of tracts around ZI, irrespective of adverse effect threshold, could be explained by the numerous functions supported by this nucleus, including motor, attention, arousal and visceral controls [31], and the adjacent FF $[25,32,42]$. The rare motor effects ( 6 times/223 tests), only noticed in the upper 10-mm of the exploration tract, could also be due to the proximity of the pyramidal tract as a consequence of the double obliquity of trajectories. Thus DBS benefit could act through different main structures, STN, ZI and FF. Even if the lateral STN offers the best ratio efficiency versus adverse effects, each of these can acutely improve symptoms. The incertitude of current diffusion, as well as of the exact anatomy and physiology for a given patient, limit the interpretation of results. Postmortem studies have also shown the complexity of relation structures/effects in the subthalamic region encompassing ZI, posteromedial or dorsolateral STN $[15,17]$. 


\section{Conclusion}

The analysis of multiple source data, relying on direct imageguided stereotactic surgery, suggests that it seems possible to determine the fine anatomy in the subthalamic region, and this with 1.5 Tesla images and under stereotactic conditions. The best microsurgical target, a compromise between benefit and adverse effects, can be confirmed in the region of the dorsolateral STN. The direct anatomical mapping emphasizes the interest to analyze the respective contributions of intra operative stimulation and neuronal activity data for a better understanding of the pathophysiology and also for an optimization of the surgical technique. Efforts to determine intimate relationships between structures, neuronal activity (spontaneous and provoked) and effects could also help the understanding of DBS results, the optimization of electrical stimulation parameters, and indirectly- the definition of the target. Nevertheless, information provided from a side-byside subthalamic analysis of data obtained during acute intraoperative conditions with exploration electrodes, must be transposed carefully to the chronic phase of stimulation, acting through bilateral stimulation via DBS electrodes.

\section{Acknowledgments}

We thank Yves Lazorthes, Marion Simonetta Moreau and Isabelle Berry from Toulouse (France), Luc Dupont Jasmin from San Francisco (USA), Antonio De Salles and Edward Mitchell from Los Angeles (USA) for their constructive comments, as well as Brian Vasey and David Brett for the language review. 
Lemaire et al. 2007

\section{References}

1. Erola T, Karinen P, Heikkinen E, Tuominen J, Haapaniemi T, Koivukangas J, Myllyla V (2005) Bilateral subthalamic nucleus stimulation improves health-related quality of life in parkinsonian patients. Parkinsonism Relat Disord 11(2): 89-94

2. Hamani C, Richter E, Schwalb JM, Lozano AM (2005) Bilateral subthalamic nucleus stimulation for Parkinson's disease: a systematic review of the clinical literature. Neurosurg 56(6): 1313-1321

3. Krack P, Batir A, Van Blercom N, Chabardes S, Fraix V, Ardouin C, Koudsie A, Limousin PD, Benazzouz A, LeBas JF, Benabid AL, Pollak P (2003) Five-year follow-up of bilateral stimulation of the subthalamic nucleus in advanced Parkinson's disease. N Engl J Med 349(20): 1925-1934

4. Krause M, Fogel W, Mayer P, Kloss M, Tronnier V (2004) Chronic inhibition of the subthalamic nucleus in Parkinson's disease. J Neurol Sci 219(1-2): 119-124

5. Rodriguez-Oroz MC, Zamarbide I, Guridi J, Palmero MR, Obeso JA (2004) Efficacy of deep brain stimulation of the subthalamic nucleus in parkinson's disease 4 years after surgery: Double blind and open label evaluation. J Neurol Neurosurg Psychiatry 75(10): 1382-1385

6. Walter BL, Vitek JL (2004) Surgical treatment for Parkinson's disease. Lancet Neurol 3(12): 719-728 7. Benazzouz A, Tai CH, Meissner W, Bioulac B, Bezard E, Gross C (2004) High-frequency stimulation of both zona incerta and subthalamic nucleus induces a similar normalization of basal ganglia metabolic activity in experimental parkinsonism. Faseb J 18(3): 528-530

8. Breit S, Schulz JB, Benabid AL (2004) Deep brain stimulation. Cell Tissue Res 318(1): 275-288

9. Filali M, Hutchison WD, Palter VN, Lozano AM, Dostrovsky JO (2004) Stimulation-induced inhibition of neuronal firing in human subthalamic nucleus. Exp Brain Res 156(3): 274-281

10. Garcia L, Audin J, D’Alessandro G, Bioulac B, Hammond C (2003) Dual effect of high-frequency stimulation on subthalamic neuron activity. J Neurosci 23(25): 8743-8751

11. Hashimoto T, Elder CM, Okun MS, Patrick SK, Vitek JL (2003) Stimulation of the subthalamic nucleus changes the firing pattern of pallidal neurons. J Neurosci 23(5): 1916-1923

12. MacKinnon CD, Webb RM, Silberstein P, Tisch S, Asselman P, Limousin P, Rothwell JC (2005) Stimulation through electrodes implanted near the subthalamic nucleus activates projections to motor areas of cerebral cortex in patients with Parkinson's disease. Eur J Neurosci 21(5): 1394-1402

13. Meissner W, Leblois A, Hansel D, Bioulac B, Gross CE, Benazzouz A, Boraud T (2005) Subthalamic high frequency stimulation resets subthalamic firing and reduces abnormal oscillations. Brain 128(Pt 10): 2372-2382 
Lemaire et al. 2007

14. Welter ML, Houeto JL, Bonnet AM, Bejjani PB, Mesnage V, Dormont D, Navarro S, Cornu P, Agid Y, Pidoux B (2004) Effects of high-frequency stimulation on subthalamic neuronal activity in Parkinsonian patients. Arch Neurol 61(1): 89-96

15. Counelis GJ, Simuni T, Forman MS, Jaggi JL, Trojanowski JQ, Baltuch GH (2003) Bilateral subthalamic nucleus deep brain stimulation for advanced pd: Correlation of intraoperative MER and postoperative MRI with neuropathological findings. Mov Disord 18(9): 1062-1065

16. Hamel W, Fietzek U, Morsnowski A, Schrader B, Herzog J, Weinert D, Pfister G, Muller D, Volkmann J, Deuschl G, Mehdorn HM (2003) Deep brain stimulation of the subthalamic nucleus in Parkinson's disease: Evaluation of active electrode contacts. J Neurol Neurosurg Psychiatry 74(8): 1036-1046

17. Henderson JM, Pell M, O’Sullivan DJ, McCusker EA, Fung VS, Hedges P, Halliday GM (2002) Postmortem analysis of bilateral subthalamic electrode implants in Parkinson's disease. Mov Disord 17(1): 133-137

18. Herzog J, Fietzek U, Hamel W, Morsnowski A, Steigerwald F, Schrader B, Weinert D, Pfister G, Muller D, Mehdorn HM, Deuschl G, Volkmann J (2004) Most effective stimulation site in subthalamic deep brain stimulation for Parkinson's disease. Mov Disord 19(9): 1050-1054

19. Saint-Cyr JA, Hoque T, Pereira LC, Dostrovsky JO, Hutchison WD, Mikulis DJ, Abosch A, Sime E, Lang AE, Lozano AM (2002) Localization of clinically effective stimulating electrodes in the human subthalamic nucleus on Magnetic Resonance Imaging. J Neurosurg 97(5): 1152-1166

20. Zincone A, Landi A, Piolti R, Appollonio I, Mariani CB, Pezzoli G, Gaini SM, Frattola L (2001) Physiologic study of the subthalamic volume. Neurol Sci 22(1): 111-112

21. Derost P, Ouchchane L, Morand D , M Ulla, PM Lbrca, Barzet M, Debilly B, Lemaire JJ, Durif F, (2007) Is DBS-STN appropriate to manage severe Parkinson's disease in an elderly population? Neurology 68:1345-1355

22. Ulla M, Thobois S, Lemaire JJ, Schmitt A, Derost P, Broussolle E, Llorca PM, Durif F (2006) Manic behaviour induced by deepbrain stimulation in Parkinson's disease: Evidence of substantia nigra implication?. J Neurol Neurosurg Psychiatry 77(12): 1363-1366

23. Magnotta VA, Gold S, Andreasen NC, Ehrhardt JC, Yuh WT (2000) Visualization of subthalamic nuclei with cortex attenuated inversion recovery MR imaging. Neuroimage 11(4): 341-346

24. Lemaire JJ, Caire F, Bony JM, Kemeny JL, Villéger A, Chazal J (2004) Contribution of 4.7 Tesla MRI in the analysis of the MRI anatomy of the human subthalamic area. Acta Neurochir (Wien) 146(8): 906-907

25. Parent A (1996) Basal ganglia: In: Parent A, Carpenter's human neuroanatomy. Williams and Wilkins, Baltimore, pp 838-843 
Lemaire et al. 2007

26. Richter EO, Hoque T, Halliday W, Lozano AM, Saint-Cyr JA (2004) Determining the position and size of the subthalamic nucleus based on magnetic resonance imaging results in patients with advanced Parkinson's disease. J Neurosurg 100(3): 541-546

27. Wang D, Strugnell W, Cowin G, Doddrell DM, Slaughter R (2004) Geometric distortion in clinical MRI systems part ii: Correction using a 3d phantom. Magn Reson Imaging 22(9): 1223-1232

28. Wang D, Strugnell W, Cowin G, Doddrell DM, Slaughter R (2004) Geometric distortion in clinical MRI systems part i: Evaluation using a 3d phantom. Magn Reson Imaging 22(9): 1211- 1221

29. Ferroli P, Franzini A, Marras C, Maccagnano E, D’Incerti L, Broggi G (2004) A simple method to assess accuracy of deep brain stimulation electrode placement: pre-operative stereotactic CT + postoperative MR image fusion. Stereotact Funct Neurosurg 82(1): 14-19

30. Pollo C, Villemure JG, Vingerhoets F, Ghika J, Maeder P, Meuli R (2004) Magnetic resonance artifact induced by the electrode Activa 3389: An in vitro and in vivo study. Acta Neurochir (Wien) 146(2): 161-164

31. Mitrofanis J (2005) Some certainty for the "Zone of uncertainty"? Exploring the function of the zona incerta. Neuroscience 130(1): 1-15

32. Parent M, Parent A (2004) The pallidofugal motor fiber system in primates. Parkinsonism Relat Disord 10(4): 203-211

33. Hamani C, Richter EO, Andrade-Souza Y, Hutchison W, Saint-Cyr JA, Lozano AM (2005) Correspondence of microelectrode mapping with magnetic resonance imaging for subthalamic nucleus procedures. Surg Neurol 63(3): $249-253$

34. Pralong E, Villemure JG, Bloch J, Pollo C, Daniels RT, Ghika J, Vingerhoets F, Tetreault MH, Debatisse D (2004) Quality index for the quantification of the information recorded along standard microelectrode tracks to the subthalamic nucleus in parkinsonian patients. Neurophysiol Clin 34(5): 209-215

35. Baker KB, Boulis NM, Rezai AL, Montgomery EB Jr (2004) Target selection using microeletrode recording. In: Israel Z, Burchiel KJ (eds) Microelectrode recording in movement disorder surgery. Thieme, New York, pp 138-151

36. Abosch A, Hutchison WD, Saint-Cyr JA, Dostrovsky JO, Lozano AM (2002) Movement-related neurons of the subthalamic nucleus in patients with Parkinson's disease. J Neurosurg 97(5): 1167-1172

37. Theodosopoulos PV, Marks WJ Jr., Christine C, Starr PA (2003) Locations of movement-related cells in the human subthalamic nucleus in Parkinson's disease. Mov Disord 18(7): 791- 798

38. Rodriguez-Oroz MC, Rodriguez M, Guridi J, Mewes K, Chockkman V, Vitek J, DeLong MR, Obeso JA (2001) The subthalamic nucleus in Parkinson's disease: Somatotopic organization and physiological characteristics. Brain 124(Pt 9): 1777-1790 
39. Patel NK, Plaha P, O’Sullivan K, McCarter R, Heywood P, Gill SS (2003) MRI directed bilateral stimulation of the subthalamic nucleus in patients with Parkinson's disease. J Neurol Neurosurg Psychiatry 74(12): 1631-1637

40. Schaltenbrand G, Bailey P (1959) Introduction to stereotaxis with an atlas of the human brain. Thieme Verlag, New York

41. Talairach J (1957) Atlas d'anatomie stéréotaxique. Repérage radiologique indirect des noyaux gris centraux des régions mésencéphalo-sous-optiques et hypothalamiques de l'homme. Masson \& Cie, Paris

42. Abrahamson EE, Moore RY (2001) The posterior hypothalamic area: Chemoarchitecture and afferent connections. Brain Res 889(1-2): 1-22 